\title{
Migrações, Saúde e Integração Social. Análise Ilustrada Pelos Portugueses EM FRANÇA
}

\author{
Maria Engrácia Leandro ${ }^{I}$ \\ Victor Manuel Terças Rodrigues ${ }^{2}$
}

Quem quiser fazer algo pelo mundo

tem que se meter no meio dele

Goethe

\section{Resumo}

As condições de vida dos imigrantes e concretamente dos portugueses em França permitem apreender as inflexões dos seus projetos e o modo como se forja a relação entre a saúde e o processo de integração social. Neste trabalho, partindo desta problemática, propomo-nos analisar três questões cruciais. A primeira estuda os meandros que envolvem a saúde e a doença. A segunda, referindo-se ao corpo do migrante e às respectivas representações, põe em perspectiva um conjunto de interpretações, a este propósito. Enfim, a terceira procura discernir a relação entre a saúde, os efeitos sanitários decorrentes das condições profissionais e sociais em que vivem os portugueses na sociedade francesa e o processo de integração social de que são alvo. A metodologia de trabalho escolhida consiste numa perspectiva dinâmica e compreensiva, baseada em estudos empíricos longitudinais sobre estes temas.

Palavras-chave: saúde, imigrante, trabalho, corpo, integração social

\section{Abstract}

The conditions of immigrants' life in France, particularly those of the Portuguese people, allow us to understand the inflections of their projects and the way the relation between health and the process of social integration takes place. In this

\footnotetext{
${ }^{1}$ Professora Catedrática de Sociologia do

Departamento de Sociologia da Universidade do Minho

e-mail: engracia@ics.uminho.pt

${ }^{2}$ Assistente Convidado de Sociologia e Demografia do

Departamento de Sociologia da Universidade do Minho

e-mail: vrodrigues@ics.uminho.pt
}

Revista Mediaçóes, Londrina, v. 11, N. 2, p. 131-152, Jul./Dez. 2006 
study, three crucial issues are considered. The first one studies the aspects that involve health and illness. The second regards the migrant's body and its respective representations and highlights a set of interpretations for such purpose. The third is the attempt to understand a relationship between health, the sanitary effects resulting from the professional and social conditions under which the Portuguese live inside the French society, and their process of social integration. The methodology consists of a dynamic and comprehensive perspective, based on longitudinal empirical studies of these issues. Keywords: health, immigrant, work, body, social integration

\section{INTRODUÇÃO}

\section{Uma Inversão de Perspectivas}

preocupação com a saúde dos migrantes não é nova, como nos mostram Gentilinie
e Duflo (1986) em alguns manuais de higiene pública e de medicina tropical.
Frequentemente, para os que emigravam legalmente, era-lhes exigido, por muitos países, antes de partirem, um exame sanitário, visando dois objectivos.

0 primeiro tinha que ver com as patologias de importação, ou seja, tornava-se imperioso prevenir alguma espécie de contágio que pudesse vir a existir devido aos imigrantes, não fossem eles portadores de doenças de índole infecciosa. Apreendida deste modo, esta concepção é algo problemática, na medida em que consegue criar a ideia e frequentemente designar os migrantes, em geral, como um "grupo de risco" do ponto de vista da saúde pública, pois poderão representar um risco para os outros (potencial contaminação) mas também para os próprios migrantes (impossível integração).

Esta dupla lógica de discriminação (com uma clínica à parte) e de naturalização (com a sua inscrição corporal), durante muito tempo impediu de pensar as questões de saúde acerca dos migrantes na sua real dimensão, uma vez que muitas das doenças que os possam atingir não são assim tão específicas, embora haja situações em que tal possa acontecer, tanto em virtude das condições de vida que, frequentemente, têm de viver, quer depois, quer antes da emigração, como do próprio contexto cultural e sociosanitário. Podemos recolher exemplos desta natureza no "Antigo regime do mal"3 (HERZLICH; PIERRET, 1984).

\footnotetext{
${ }^{3}$ Aquele - no essencial desapareceu por volta do século XVII-XVIII - no qual a doença é marcada por três características essenciais: 0 número, a impotência e a morte e a exclusão social, inclusive dos familiares mais próximos.
} 
$\mathrm{Na}$ Europa ocidental, assinala-se a primeira grande peste negra, que fazendo as primeiras vítimas em Messina em Outubro de 1347, foi trazida para a Itália e daí para toda a Europa, pelos passageiros das 12 galerias provenientes de Kaffa na Crimeia. $\mathrm{Na}$ Europa, durante mais de 4 séculos, dizimou mais de 26 milhões de pessoas. Neste período havia uma grande tendência das pessoas sãs para abandonarem os doentes com medo dos riscos de contágio, o que provoca grande desordem social, em vez de integração social e reforço dos laços sociais. Como numerosas epidemias, a peste está associada às grandes deslocações, às viagens e às guerras, como aconteceu, por exemplo, com a gripe, a varíola, o sarampo e a escarlatina importadas para o México pelos colonizadores espanhóis, provocando a exterminação de muitos índios, mas também com a importação da sífilis para Itália pelos navegadores de Cristóvão Colombo, durante a guerra de Nápoles em 1494, difundindo-se, depois, em grande escala por toda a Europa. Igualmente, do Oriente em 1832 vem a cólera que atinge Paris e depois se difunde para muitos outros locais.

Assim, podemos dizer que, em determinadas circunstâncias, não são apenas as pessoas que emigram, mas com elas partem, também, certas doenças mais ou menos contagiosas. Mais perto de nós, ao ser descoberto, também o HIV/Aids foi de imediato associado à vinda dos imigrantes do Haiti para os Estados Unidos (NOSSA, 2001), o que rapidamente veio a ser desmentido. Mesmo assim, continuam a haver muitos fantasmas que pairam entre as populações das ditas sociedades de acolhimento, sobretudo no que se refere aos imigrantes que chegam recentemente da África, dado o impacto que esta pandemia aí vem atingido. Hoje teme-se a disseminação da gripe das aves através dos viajantes.

0 segundo objectivo prende-se com factores de ordem econômica. Se como diz George (1977) "[...] os cruzados partiram para salvar a alma, os 'voluntários' para alcançar a glória, os emigrantes para fazer fortuna", estes últimos podem conseguir estes objectivos através do afinco ao trabalho e à lógica da poupança. Ora, para isso, a saúde representa um capital humano e económico importante: em primeiro lugar para poderem trabalhar e serem aceites, sem reservas, pelas respectivas identidades patronais e até pela sociedade em geral, uma vez que assim serão rentáveis e não aumentarão as despesas da Segurança Social com o tratamento da doença. Neste sentido, pode falar-se mesmo de uma "selecção social através da saúde" (DRULHE, 1996).

Numa perspectiva sociológica, o trabalho de campo que realizamos no concelho de Vila Verde, no norte de Portugal, em 2001, junto de um grupo de imigrantes da Ucrânia, atesta esta realidade. Entre os nossos entrevistados um sofria de doença. No entanto, mostrava uma enorme preocupação em não o manifestar, sobretudo de maneira 
a que a entidade patronal o pudesse vir a saber, com receio que o pudesse vir a despedir, ainda que o guia português da saúde para os imigrantes se insurja contra situações desta natureza. Na verdade, em relação ao mercado de trabalho, os migrantes vivem, muitas vezes, uma situação de maior precariedade que não lhes passa despercebida. Por outro lado, têm consciência de que a saúde faz parte de um critério de selecção por parte das entidades patronais. Daí que o pretexto da doença, quando esta se manifesta, apareça como um forte alibi para 0 despedimento, quiçá até para deixar as pessoas abandonadas à sua sorte e ainda mais se se trata de ilegais ou de migrantes de curta duração.

Casos destes também os encontrámos em França entre 1980 e 2006, junto de imigrantes portugueses, onde durante este período temos prosseguido investigação sobre vários aspectos, inclusive a relação entre a saúde e o processo de integração social, pesquisa que ao longo do tempo, serve de suporte a este trabalho. A última foi realizada no $2^{\circ}$ trimestre de 2006, junto de 50 pessoas: 42 portuguesas e 8 francesas cujas características estão visualizadas no quadro $n^{0} 1$.

Quatro aspectos principais são apresentados neste trabalho. 0 primeiro prendese com a relação entre a saúde e o trabalho em contexto migratório. 0 segundo com a relação entre a saúde, a doença e as condições socio-culturais de existência. 0 terceiro com as representações acerca do corpo, os males que atingem o corpo dos imigrantes e mais concretamente dos portugueses em França e as consequências que daí podem decorrer, tanto profissionais como humanas e sociais. Por fim, a quarta analisa a saúde como factor que favorece ou não a integração social dos portugueses em França.

\section{Questões de Método}

Quanto à metodologia escolhida, fundamenta-se, em primeiro lugar, no critério da maior implicação possível dos sujeitos seleccionados da nossa amostra, dado termos adoptado técnicas de coleta de dados de cunho qualitativo. Estas justificam-se em virtude de pretendermos recolher dados aprofundados que nos permitissem apreender o sentido que os actores imprimem às suas atitudes e comportamentos. Dando-lhes a palavra, no sentido de poderem exprimir-se à vontade, ainda que no quadro da entrevista ela fosse semi-directiva, pretendíamos, ao longo deste trabalho, não falar sobre os portugueses e franceses entrevistados ou em nome deles, mas antes, a partir do que nos diziam, falar do que sentiam e das próprias interpretações acerca da realidade em estudo: a relação que estes indivíduos estabelecem entre a saúde e o processo de integração social na sociedade francesa. 
Com estas perspectivas, procedemos à aplicação do pré-teste de entrevista. Só depois seleccionámos as pessoas a entrevistar cujos critérios estão visualizados no quadro $\mathrm{n}^{0} 1$, com a excepção da nacionalidade, mas que já foi indicada anteriormente.

Compreender-se-á que na sequência de tais considerações, que entre as pessoas entrevistadas havia quem vivesse situações mais complexas do que outras, afigurandose, assim, necessário aceitar, desde o princípio, a eventualidade de trilhar caminhos que abrangessem também a observação directa e participante, a fim de compreendermos intrinsecamente os modos como avaliam a saúde, a doença, os serviços de saúde locais e o processo de integração social no seu todo. Procurámos, então, manter uma escuta disponivel, tendo sempre presente a "neutralidade axiológica" (WEBER, 1971). Com estas perspectivas, todas as pessoas solicitadas a concederem-nos uma entrevista ou a permitirem que as acompanhássemos noutras actividades da vida do dia a dia, se mostraram inteiramente disponíveis e bastante colaboradoras.

Os problemas sanitários e/ou sociais com que se debatem, e que foram abordados no decorrer das entrevistas, ou detectados através da observação directa e participante, revelaram rapidamente a sua visão da vida, da saúde, da doença, do corpo e do meio social envolvente, bem como as inflexões que foram introduzindo nos projectos migratórios, visando um processo de integração social mais harmonioso e consistente. É, pois, a partir dos dados recolhidos através deste conjunto de técnicas metodológicas que tentámos exercer um discernimento capaz de captar o alcance das mensagens que nos foram transmitidas.

Quadro 1. Características da amostra seleccionada

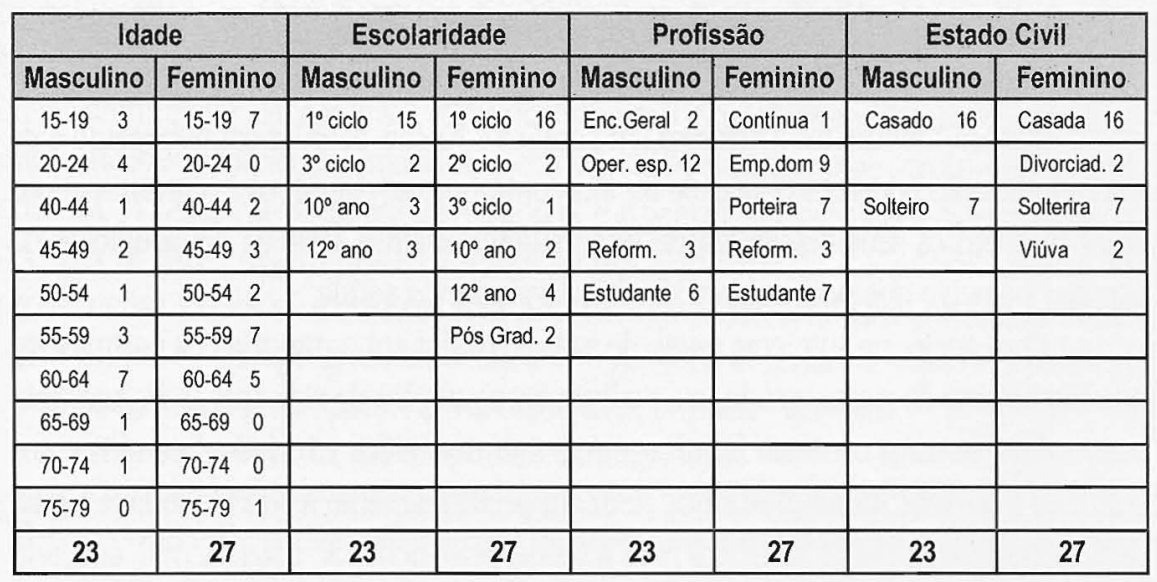




\section{Saúde, Trabalho E Capacidade de Subsistir}

Para a configuração precisa da relação como a que agora se enuncia, múltiplos são os indicadores invocáveis. Por exemplo: saúde e trabalho; relações sociais de produção e exploração ou situação comum de indivíduos que têm as mesmas oportunidades no mercado de trabalho e do acesso aos bens, condições de existência e experiências pessoais (WEBER, 1971); saúde e dinâmica dos grupos sociais (TOURAINE, 1978), etc. 0 que se pode, então, dizer é que há uma relação intrínseca entre a saúde, a pertença social e 0 trabalho, uma vez que o desgaste diferencial provocado por este engloba estas três vertentes. Com efeito, todos os estudos estatísticos realizados sobre estas matérias têm revelado que as classes médias ou altas, exercendo profissões de menor desgaste físico e mental (BASTIDE, 1965) e recorrendo mais aos serviços de prevenção da saúde, são menos atingidas pela doença e têm maior esperança de vida (DRULHE, 1996). Ora, geralmente, passa-se o inverso para os migrantes que, sendo colocados na base da pirâmide da estratificação social e, realizando, normalmente, os trabalhos mais duros, insalubres e mal pagos, frequentemente recusados pelos autóctones, são mais atingidos pelo desgaste físico e psíquico e, em consequência, por doenças mais graves e mais mortíferas. Sendo assim, a sua integração profissional e social e a sua condição sanitária são também elas estratificadas.

Mas a preservação e a promoção da saúde exercem também repercussões sobre outras realidades, como seja a capacidade de subsistir às mudanças do clima como nos falavam os portugueses na Alemanha (LEANDRO, 2002a) e em França, referindo-se aos primeiros tempos da imigração, da possível exiguidade e deficiências sanitárias da habitação tal o caso das porteiras, das dificuldades de adaptação a novas dietas alimentares, do confronto com uma nova língua que têm de aprender para poderem comunicar com a sociedade envolvente, duma provável ausência da família, sobretudo nos primeiro tempos, o que pode produzir efeitos sobre a saúde psíquica, mas também da inospitalidade ou pelo menos da indiferença com que muitas vezes são vistos, quando afinal estavam habituados a viverem em contextos sociais de inter-conhecimento e de inter-ajuda. Não podemos deixar de ter em conta que, em geral, os imigrantes e, por vezes também os seus descendentes, estão sujeitos a uma série de acumulações de carácter negativo que nem sempre são favoráveis para a saúde.

Com efeito, na sua terra natal, de índole rural, para a maioria dos portugueses que são objecto do nosso estudo, até podiam ter condições de vida frugal. Porém, esta desenrolava-se num contexto familiar e social enriquecidos e forjados por elementos culturais e porventura religiosos que marcam profundamente a sua identidade e que, decerto, produzem efeitos benéficos para a saúde, pelo menos ao nível mental, podendo 
por exemplo, prevenir o stress e as depressões. Aliás, é cada vez mais conhecido por aqueles (profissionais ou não) que se interessam pelo estudo dos factores que mais contribuem para a manutenção da saúde e a concebem não apenas na sua dimensão biológica, mas também psíquica, social e dinâmica, que as condições e estilos de vida, os aspectos emocionais, a rede de relações familiares e sociais, com particular destaque para os suportes sociais, como o afirmam Le Disert (1985), Adam e Herzlich (1994), Fassin (1996), Leandro (2001), Machado (2003), podem exercer influências muito benéficas sobre a saúde e 0 inverso para a sua ausência.

Em paralelo, é necessário reforçar a prevenção da doença. As estatísticas oficiais são claras: de acordo com o Ministério da saúde norte-americano, o nível de saúde de uma população é influenciado apenas em $10 \%$ pelos serviços de saúde, cabendo a factores hereditários (19\%), factores ambientais (19\%), e sobretudo aos modos e estilos de vida (52\%), o papel determinante no bem estar físico e psíquico das pessoas (LOPES et al., 2000). Isto é, evitando o stress, não fumando, conduzindo com prudência, comendo e bebendo de forma regrada e usufruindo de um ambiente familiar e social harmoniosos, é possível diminuir drasticamente as doenças que nos afligem.

Estas atitudes e comportamentos, com particular destaque para os últimos, podem assumir ainda maior importância para os portugueses em França, uma vez que tendem a ser mais votados ao isolamento e sujeitos à saudade, particularmente nos primeiros tempos da imigração. Ao invés, à medida que o tempo passa, que o reagrupamento familiar tem lugar e que o processo de integração social se vai tornando mais consistente, tende a instaurar-se uma maior abertura com a sociedade envolvente, o que favorece 0 bem-estar individual, familiar e social, que se vem revelando tão importante para a saúde, como ademais o preconiza a OMS, em 1946, na sua tão célebre definição de saúde. ${ }^{4}$

De qualquer modo, para os países recebedores de mão-de-obra imigrante, a razão de ser da mesma tem que ver, em primeiro lugar, com o trabalho, sem o qual o imigrante não tem valor próprio em virtude de uma dupla lógica: o que representa e vale por si mesmo e é capaz de fazer, o que vale para a sua família e para a entidade patronal que o recebe mais na qualidade de homo faber, oeconimicus e homo sanitas para poder ser produtivo e rentável, do que bomo socius, que também tem direito a

\footnotetext{
${ }^{4}$ Esta definição, no seu primeiro parágrafo, estipula que "a saúde é o mais completo bem-estar físico, mental e social e não só a ausência de doença ou de enfermidade". Esta definição tem o mérito de introduzir o meio social e de inscrever a saúde como um dos direitos fundamentais de todos os humanos, independente da etnia, da religião, das opiniões políticas, da sua condição económica e social e do seu estatuto de nacional ou de estrangeiro inclusive imigrante, ainda que ao longo do tempo venha sendo objecto de várias críticas, em virtude do seu carácter muito geral, algo estático, tecnocrata, idealista, quiçá demagógico.
} 
uma vida social condigna, à doença e ao tratamento adequado para readquirir a saúde em boas condições, tal como está explícito no art ${ }^{\circ} 25$, I, da Declaração Universal dos Direitos do Homem. De facto, a saúde é assimilada à capacidade de poder trabalhar ao passo que a doença à incapacidade laboral, a tal ponto que para os migrantes em idade activa, estar doente ou parar de trabalhar são ainda equivalentes. De resto, Parsons (1951, p. 19), falando do 'papel do doente' considera que mesmo não voluntária, a doença não é menos uma forma de desvio social, impedindo o indivíduo de realizar as tarefas que thes estão atribuídas...". Por sua vez, Sayad (1999, p. 260), referindo-se aos imigrantes, considera que "...a doença, sobretudo quando impede de poder voltar a trabalhar, tem o triste privilégio de pronunciar de maneira firme e definitiva a negação do imigrante".

Falando ainda das doenças que mais podem atingir os imigrantes, de maneira mais geral, hoje, também se tem medo do que possa acontecer com o regresso da tuberculose, que nos países de imigração chega a ter maior incidência sobre a população imigrante, em virtude do desgaste físico, das deficiências alimentares, da habitação e do trabalho duro e insalubre, como acontece em Portugal, designadamente na área de Lisboa (MENDES, 1999), onde está concentrada a grande maioria da população imigrante.

Ora, o que se verifica é que não é apenas pelo facto de ser imigrante que se tem mais propensão para esta ou para aquela doença. Idênticas diferenças podem encontrarse no seio da população autóctone, tendo em conta as desigualdades sociais e até geográficas, como, por exemplo, habitar no meio rural ou no meio urbano. Daí que a diferença não possa ser interpretada só em termos culturais e étnicos, mas antes correlacionada com as condições sociais de existência, como nos revelam os trabalhos de Fassin (1997), os de Hiach $(1991,1998)$ e os de Leandro (2000) realizados sobre estas questões. Perante estes factos são, por um lado, a familiaridade pacientemente adquirida com esta condição estrangeira inicial e, por outro, o trabalho reflexivo, frequentemente ancorado numa análise política, que vão permitir ultrapassar o absoluto da diferença, isto é, poder pensar o Outro como diferente de si e, no entanto, o mesmo que eu.

Há aqui uma interrogação antropológica entre a "unidade do Homem" e a "pluralidade das culturas" que, ao mesmo tempo, questiona os actores do sector sociosanitário que se confrontam com doentes imigrantes. Por vezes, para estes, a incapacidade de exprimir a doença e o sofrimento na língua do país e na linguagem dos profissionais de saúde como os médicos, pode criar um hiato entre uns e outros que pode agravar a situação e até aumentar a distância entre eles, o que pode contribuir 
ainda para piorar a doença. Disto se davam conta muitos médicos em França em relação aos portugueses, vindo por isso, a co-organizar com os sociólogos do Departamento de Sociologia da Universidade do Minho que se interessam por estas questões um colóquio internacional intitulado: "Mieux connaître pour mieux soigner: les immigrés portugais", que teve lugar a 26 e 27 de Maio de 1996. Procuravam, assim, conhecer a cultura portuguesa na sua essência e no local para desta maneira, poderem prestar melhores serviços médicos junto dos seus pacientes portugueses.

Compreender-se-á, na sequência de tais considerações sobre as manifestações da doença e o modo de as exprimir, bem como as determinantes sociais da saúde e da relação entre médicos e utilizadores dos serviços de saúde, quanto os modelos que outrora serviam para classificar as condições sanitárias dos imigrantes, significativamente designadas como "saúde dos imigrantes" e repartidos em "patologia da importação", passando para a "patologia da aquisição" e mais tarde para a "patologia da adaptação", hoje não dão bem conta da realidade sanitária vivida por eles. Actualmente, a análise terá que ter em conta as lógicas universais dos problemas com que são confrontados, as especificidades socio-económicas e socio-jurídicas da sua situação.

Revestem igualmente importância os próprios traços da(s) cultura(s) a que pertencem, a religião e os valores que perfilham. Sobre este aspecto, importa destacar que com o decorrer do tempo a cultura migrante vai-se tornando numa cultura de mistura, na medida em que englobando elementos do passado e do presente, vai forjando, tanto um processo de "sincretismo", como até de "simbiose" (ABOU, 1981). Neste último caso, a situação é mais comum para as gerações mais novas, maioritariamente nascidas em França, sem no entanto deixarem de ser portuguesas, em virtude de uma grande tendência para guardarem a dupla nacionalidade. Aqui, desde a sua concepção são seguidas pelos serviços de saúde franceses, bastante diferente do que viveram os pais em Portugal antes da emigração, em que se recorria muito menos aos serviços de saúde em idênticas circunstâncias.

Aludindo, depois disto, às tendências que possam existir para a estigmatização (GOFFMAN, 1982), relativa aos imigrantes, inclusive em termos de saúde, como acima o indicamos, importa relevar que para ultrapassar esta situação, é imperioso o combate às desigualdades e discriminações sociais em geral e da saúde em particular que, por vezes, assolam os imigrantes e as suas famílias. Frequentemente, uma maior morbilidade dos imigrantes resulta mais da precariedade das situações em que são votados a viver com a sua família, do que de qualquer efeito biológico, como muitas vezes se quer fazer crer, salvaguardando o caso das doenças hereditárias. Aliás, como o afirma Lazorthes (1998, p. 355), "nenhuma doença está exclusivamente sob a dependência de causas 
endógenas ou de causas exógenas... mas corresponde antes à etiologia e à patogenia que a envolvem". Uma digressão, breve e convenientemente simplificada sobre o processo de produção da doença em contexto migratório, como o refere o mesmo autor, tem que ver com os modos e estilos de vida dos imigrantes e o meio envolvente. Fazendo a relação entre os hábitos alimentares e o cancro do estômago e do pulmão nos Estados Unidos, diz que "[...] a frequência do cancro do estômago diminuiu nos últimos 30 anos, ao passo que o cancro do pulmão aumentou para 400\%. Porém, logo que as populações atingidas por estas enfermidades emigram, a proporção do seu estado cancerígeno torna-se semelhante ao das populações para onde foram viver" (LAZORTHES, 1998, p. 361).

\section{A Expressão da Doença e do Sofrimento Através do Corpo}

A doença, tal como a morte, é inerente à vida (THOMAS, 1991). Não sendo específica do Homem, atingem tudo o que vive. Contudo, todas as considerações desenvolvidas a propósito da saúde e da doença dos imigrantes, portugueses ou não, têm de ser relacionadas com o corpo. Aliás, segundo Le Breton (1990, p. 7), "[...] viver é reduzir continuamente o mundo ao seu corpo através da simbologia que ele incarna. A existência humana é corporal... Porque ele está no cerne da acção individual e colectiva, no centro do simbolismo social, o corpo é um analisador de grande alcance para compreender melhor o presente".

Daí que valha a pena suscitar alguma reflexão acerca da doença e do corpo em contexto migratório. Como já dissemos, é frequente que a doença se manifeste com mais frequência em consequência da adaptação a uma nova sociedade, possivelmente à vida urbana, do desgaste físico e duma nova gestão da vida individual, familiar e colectiva que as condições de imigrante impõem, pelo menos nos primeiros tempos. Assim, a morbilidade pode manifestar-se através de vários sintomas de ordem física e psicossocial, neste último caso podendo ainda incluir vestígios de um passado associadas, por exemplo, à religião e à magia. Não raro, nos anos oitenta-noventa do século passado, ao longo do nosso trabalho de campo, referindo-nos ao sofrimento desencadeado pela doença, alguns dos nossos interlocutores diziam-nos: "temos que sofrer porque Cristo também sofreu". Hoje os portugueses revelam-se menos conformistas. Mesmo assim, sabemos, também, através da observação directa e das confidências que nos são feitas, que em situações desesperadas para as quais a medicina ainda não oferece resposta cabal, alguns portugueses continuam a recorrer a promessas aos Santos e a Nossa Senhora e até a agentes mais relacionados com a magia, quando pessoas de outras 
condições sociais e culturais se dirigirem antes aos psicólogos, psiquiatras e psicanalistas. E isto apesar de, em geral, considerarem que os serviços de saúde em França são muito bons, bastante acessíveis e os médicos muito acolhedores.

Interessa anotar por outro lado, que o peso específico das suas condições de vida e de trabalho, as condições habitacionais e climatéricas, as dificuldades de comunicação dos primeiros tempos, a maior ou menor exigência do processo de adaptação, em princípio, são propícias ao desencadear de doenças que em condições de vida diferentes poderiam não chegar a manifestar-se. Os trabalhos de campo que realizámos, tanto em França como em Portugal, inclusive entrevistas junto de médicos de família que têm pacientes imigrantes, num e noutro país, frequentemente, nos revelaram que a doença se manifesta com maior incidência através de lombalgias, em virtude do esforço laboral que exige mais energia e desgaste dos membros e da coluna; de perturbações digestivas devido à mudança de regimes alimentares; do sono em virtude de horários de trabalho prolongados e das distâncias que têm que percorrer em meios de transporte ou ainda do trabalho por turnos e da poluição sonora das grandes cidades, como aquelas onde vive a grande maioria dos portugueses em França; de problemas cardiovasculares, tanto em virtude de predisposições hereditárias, como de vários tipos de ansiedade, do stress sofrido ao longo dos anos, formando um conjunto patogénico, que tal como noutras situações pode ser considerado "o mal do século" (LAZORTHES, 1998; QUARTILHO, 2001; LEANDR0 et al., 2002; MACHADO, 2003).

A estas enfermidades, acrescenta-se ainda um conjunto de doenças crónicas e degenerativas mais associadas ao envelhecimento, embora entre os imigrantes portugueses e quiçá entre outros, tendam a manifestar-se mais cedo, em virtude das suas condições de existência: artroses, arteriosclerose, hipertensão arterial, diabetes, colesterol, cancro, reumatismo, e doença de Alzheimer ou Parkinson, entre outras. Há, também que ter em conta as situações de humor com tendência para a depressão, a ansiedade, a angústia e a despersonalização, mas onde se podem manifestar também perturbações amnésicas, desorientações temporais e espaciais e isolamento, conflitos interiores, tradução bastante simbólica da perda identitária (LE BRETON, 1989).

Não admira, pois, que a doença do imigrante na sua relação com o social, isto é, aquela que mais do que a de ninguém decorre das suas duras condições de vida, esteja mais associada às influências psicossociais (LEANDR0, 2005). Com efeito, por exemplo, Victor Hugo (1862) considerava que a tuberculose era uma doença da classe operária, porque era acima de tudo uma doença da miséria e do desgaste. Ora, a maioria dos imigrantes, inclusive os portugueses em França e noutros países, sem serem miseráveis (LEANDR0, 1992-1995), pertencem à classe operária. Deste modo, a doença 
dos migrantes, pelo menos em parte, pode ser definida pelo lugar que ocupam no conjunto social onde vivem. Ademais, nesta perspectiva, Sontag (1980) designa a doença como "metáfora do social". Acontece ainda, que em caso de patologia comparável procuram mais tarde os serviços médicos do que, por exemplo, os autóctones. Os seus filhos são mais abrangidos pelo insucesso escolar e, actualmente, correm mais riscos perante o desemprego. Desta maneira, eles acumulam muito mais desigualdades sociais que, ao mesmo tempo, se podem tornar em desigualdades sanitárias.

Neste contexto, a doença ou acidente podendo atingir apenas este ou aquele órgão, risca de generalizar-se a todo o corpo, no sentido do sofrimento por todo o lado, provocando, então, uma expressão de tristeza e de angústia, introduzindo paragens e rupturas, a partir das quais se podem desenvolver, muitas vezes, síndromas desconcertantes que não correspondem aos dados da medicina baseada, ela mesma, em sinais objectivos, sintomas orgânicos, na investigação instrumental sancionada por um diagnóstico, conduzindo a um receituário ou a terapias que podem não se ajustar à verdadeira realidade da doença vivida pelos imigrantes (LE BRETON, 1989; SAYAD, 1999). Por exemplo, uma das contradições que pode ser vivida a este nível é aquela que afecta as relações que o imigrante tem com o seu próprio corpo - corpo como objecto de representação e de representação de si mesmo, pois que o corpo é habitado por todo o grupo que comporta - corpo como instrumento de trabalho e como espaço de expressão da doença mas, muitas vezes, incompreendido aos olhos dos outros. Podem estar neste caso as depressões e as ansiedades.

É, também, através da doença e do que se lhe segue, que melhor se dão a ver as contradições constitutivas da condição do imigrante. Porque o imigrante não tem sentido, aos seus próprios olhos e aos do seu meio familiar, profissional e social, e no limite não existe, a não ser através do trabalho que faz com o seu corpo. Daí que para o imigrante, a doença por si mesma, mas possivelmente ainda mais pela impossibilidade de trabalhar que arrasta consigo, é frequentemente vivida como a sua própria negação.

De um tal modo de conceber esta realidade, desprende-se uma atitude que leva a compreender o sofrimento através do corpo, mas que é apreendido diferentemente em virtude da pertença cultural, um corpo instrumento de trabalho, sujeito a doenças profissionais ou acidentes de trabalho que, deste modo, sofre e se degrada e que só é tido em conta pela observação médica. Mesmo assim, em tais circunstâncias o corpo pode tornar-se no único meio de expressão quando reina a incomunicabilidade linguística. É desta maneira que se constitui o síndroma do mal por todo o lado, fonte de incompreensão, de rejeição, de recusas exprimidas correntemente pelo termo de "sinistrose", que segundo (SAYAD, 1999, p. 266) é, "[...] uma atitude 'patológica' do 
ferido que recusa reconhecer a sua cura, porque pensa, de boa fé, que não obteve em virtude da lei, uma justa reparação imposta; no fundo trata-se de um 'reivincador' cuja 'reivindicação' parte de uma situação excessiva de direito a ser indeminizado". Frise-se que "sinistrose" é um termo que figura muitas vezes nos relatórios dos especialistas quando não conseguem compreender o verdadeiro alcance da doença que se manifesta no imigrante. É neste corpo que se inscrevem e ressoam todas as feridas que se foram acumulando em silêncio e é ele que as exprime à sua maneira. Deste modo, a doença torna-se linguagem para exprimir o sofrimento, os insucessos, a frustração, a desaculturação, a incompreensão, em suma toda a espécie de sofrimento acumulado ao longo do percurso migratório (LE BRETON, 1989), ou até talvez antes, tendo em conta as razões que vieram a desencadear a emigração de cariz económico: pobreza, desemprego, baixos salários, privações e impossibilidade de realizar no país as suas aspirações pessoais e familiares (LEANDRO, 1992-1995).

Frise-se, ainda, que para os portugueses em França, a doença, enquanto ruptura de um equilíbrio físico e psíquico provocada por uma lesão ou por um distúrbio funcional, tem uma consequência formal: a interrupção do projecto (SARTRE, 1986), que visa a melhoria das condições de vida para si e para os seus.

Ora, para os portugueses, como de resto para os demais imigrantes, a doença faz deles um trabalhador inútil, o que lhes faz perder as suas referências, entre as quais o trabalho era a mais notória. A actividade profissional, enquanto exercida, éjustificativa, tanto aos olhos da comunidade de origem (projecto económico), como da sociedade de acolhimento (valor trabalho). Ademais, seja qual for a relação que os portugueses guardam entre emigração e imigração, a partir da qual se consideram emigrantes e imigrantes, uma das contradições maiores que aí se encontra é a que afecta as relações que mantêm com o seu próprio corpo. Corpo como objecto de representação e representação do mesmo, corpo como espaço de afecto mas também de intelecto, uma vez que o corpo é habitado por todo o grupo que se transporta em si próprio, corpo que trabalha e corpo como lugar de expressão da doença (SAYAD, 1999). De resto, uma das nossas entrevistadas, sendo advertida pelo médico de que teria que abrandar o seu ritmo de trabalho, em virtude de sofrer de doença cardiovascular que exigia determinados cuidados de saúde, dizia-nos que, mesmo tendo consciência disso e o que podia representar de preocupação com os filhos ainda crianças que "tinba um corpo era para trabalhar" (Mulher, porteira, 43 anos).

Frequentemente, o corpo do imigrante acaba por ser objecto de muitas contradições e incompreensões que podem acumular todas as outras e abranger tanto a população em geral, as entidades patronais, os profissionais de saúde designadamente 
os médicos e os enfermeiros, como os próprios imigrantes. Tenha-se presente que é quando a doença ou acidente sobrevém e as consequências daí decorrentes, que se dão a ver melhor as contradições constitutivas da condição do imigrante. Porque o imigrante não existe nem tem razão de ser, quer aos olhos dos que o rodeiam, quer aos seus próprios olhos, a não ser através do trabalho, pois que ao e/imigrar é movido por um projecto que conta com a saúde, o trabalho e o salário para, assim, poder aceder a uma vida melhor. Ora doente não pode, de modo algum, atingir estes objectivos (LEANDRO, 1994). Ao mesmo tempo, frequentemente, é visto pela entidade patronal como utilidade marginal a consumir. Vários dos nossos interlocutores portugueses em França nos transmitiram esta sensação, quando, por exemplo, são atingidos por doença profissional, sendo obrigados a mudar de actividade ou a aceitar uma reforma antecipada. Mais ainda, um imigrante desempregado e doente, pode vir a sofrer de uma dupla acusação: não produz e gasta recursos da Segurança Social. Acusações desta natureza são muito frequentes em França, designadamente por Jean-Marie Le Pen (2007), e os seus seguidores, líder da Frente Nacional que "[...] continua a considerar a imigração como a causa de todos os problemas em França e o seu fim como a solução para o desemprego, a falta de habitação, o défice da segurança social, a delinquência juvenil e a vida pública" (Jornal Público, 25/02/07, p. 16).

Refira-se ainda, que, de facto, com a doença é retirado ao imigrante o estatuto que tem nas sendas da imigração. Só a cura pode restaurar o equilíbrio perdido e permitir ao corpo afirmar-se na sua plenitude. Muitos, até por falta de compreensão entre médico e doente, em virtude das dificuldades daquele que não fala correctamente a mesma língua e muito menos a linguagem do médico, o imigrante doente é duplamente incompreendido: na maneira como se exprime e sobretudo quando se trata de relatar 0 sofrimento ou de diagnosticar o que envolve a doença.

Exactamente em relação a França, nos anos noventa do século passado, ${ }^{5}$ vários médicos nos disseram que, por vezes, tinham dificuldade em apreender as doenças que assolavam muitas mulheres portuguesas, que se queixavam quase exclusivamente de dores de cabeça e de problemas de índole cardiológica. Sendo assim, à primeira vista, a tendência do médico ia no sentido de receitar analgésicos e calmantes com todos os efeitos secundários que daí podiam decorrer. Sob o ponto de vista cardiológico, a situação clínica não apresentava os problemas de que se queixavam. Só com o decorrer do tempo, se foram dando conta que a questão era mais bem complexa, pois que por detrás destas

\footnotetext{
' Colloque: "Mieux connaître pour mieux soigner: les immigrés portugais", organizado pelo Instituto de Ciências Sociais da Universidade do Minho - Portugal e a SFTG (Société de Formation Thérapeutique du Généraliste France, 1996.
} 
verbalizações do mal que sofriam se escondiam muitos outros problemas relacionados não apenas com o foro biológico, mas também psicológico. Tornava-se, então, imperioso conhecer muitos outros aspectos da vida destas mulheres abrangendo a família, as relações inter-pessoais, a natureza dos laços sociais, os modos de vida, as condições de trabalho e habitacionais, os projectos migratórios e os horários de trabalho intensos para os realizar rapidamente, o cansaço, bem como o seu passado cultural, educativo e religioso, uma vez que qualquer análise médica, em situação migratória, que queira negligenciar ou suprimir estas influências pode ser votada ao fracasso.

Como o corpo do migrante é essencialmente um corpo que trabalha (LEANDRO, et al., 2002b), mas também o que permite a comunicação com o outro, um corpo que foi objecto de um processo de socialização elaborado num meio cultural específico, forja também os indivíduos para interiorizarem um babitus (BOURDIEU, 1970) próprio de um determinado meio social e cultural. Por esta razão, urge combater os preconceitos e procurar compreender melhor as culturas ignoradas e por vezes até rejeitadas e, portanto enriquecedoras, visando compreender melhor as diferenças de comportamento dos portugueses em França perante a saúde e a doença, mais próximos da cultura francesa do que, por exemplo, os magrebinos, designadamente em caso de hospitalização como bem o analisa Le Breton (1989). Nestas circunstâncias, os limites de pudor em relação ao corpo doente que se dá a ver aos médicos e aos enfermeiros são distintos de umas culturas para as outras: menos rígidos nas culturas francesa e portuguesa e 0 invés na cultura muçulmana.

Um outro aspecto que importa ter em conta na relação com o corpo, a saúde e a doença, prende-se com influências culturais aldeãs mais generalizadas, antes da emigração como acontecia com a grande maioria dos emigrantes portugueses. Aqui tendiam a ser homens e mulheres comunitários. Porém, na nova sociedade através dos seus mecanismos, das novas atitudes que vão interiorizando e dos comportamentos adoptados, aprendem a tornar-se em indivíduos individualizados. 0 novo meio, onde os valores da modernidade estão mais solidificados, preconiza como um dos valores fundamentais a individualidade. Com o decorrer do tempo, os portugueses vão-se familiarizando mais com estes valores e adquirindo novos comportamentos, tal como 0 revela Sayad (1977) para o caso dos magrebinos. No caso dos portugueses, esta nova cultura exige que estes homens e mulheres comunitários se diferenciem de si próprios individualizando-se, ainda que mantenham uma certa vida comunitária intramuros, através das Associações e das Missões religiosas portuguesas. Aqui podem vir a encontrar redes de relações ou até suportes sociais de que falámos anteriormente, que fazem com que se porventura o corpo individualizado é atingido pela doença, possam contar com 
o apoio dos compatriotas e amigos, o que é muito frequente em situações desta natureza, como pudemos constatar através do trabalho de terreno que temos vindo a realizar ao longo dos anos. Constatamos, pois, que quando a doença ou até a morte sobrevém, para além do recurso aos respectivos serviços de saúde ou funerários, a solidariedade entre os portugueses que residem em França ainda é muito forte nesta alturas.

\section{A Saúde como Factor de Integração Social}

Entre os nossos entrevistados, a grande maioria já vive em França há cerca de 20,30, 40 e mais anos e 12 já nasceram em França, onde uns e outros pensam continuar a viver. É certo que os nascidos aqui não podem ser considerados imigrantes mas tão só portugueses ou franceses, ou os dois ao mesmo tempo. De qualquer modo, o que pretendemos estudar, de modo singular, é a situação dos imigrantes portugueses em França e mesmo dos que aqui nasceram, que na generalidade dos casos tendo a dupla nacionalidade são também portugueses. Seja como for, 36 dos nossos entrevistados têm um projecto de instalação definitiva neste país, vivendo a maioria em habitação própria, ou numa residência de função como a de porteira, chegam, neste caso, a beneficiar da propriedade de uma residência secundária. Porém, dois casais, passando a usufruir da reforma já há algum tempo, decidiram, desde a reforma, enveredar por um percurso de migração circular, ou seja, passam o tempo mais quente da Primavera e do Verão em Portugal e o mais frio do Outono e do Inverno em França, onde também adquiriram casa, exactamente para poderem usufruir das vantagens que encontram nesta modalidade de deslocação/instalação, mormente em termos dos serviços de saúde, do clima e das condições que, por exemplo, usufruem em França para diminuir os efeitos do rigor do inverno no que toca ao aquecimento da casa e manter uma relação de proximidade com os filhos e os netos. As visitas entre uns e outros, quer num país quer noutro, são muito frequentes.

Frise-se, todavia, no que se refere à saúde e à doença, pois ambos os casais sofrem de algumas doenças crónicas: hipertensão, colesterol, artrose, diabetes e reumatismo, que é em França que procuram os serviços de saúde de que precisam, sendo seguidos pelos médicos que os têm acompanhado ao longo do seu percurso de vida neste país. Por exemplo, nas últimas semanas antecedendo o regresso fazem as consultas médicas que julgam necessárias ou sugeridas pelo seu médico de família, assim como os respectivos exames e regressam a Portugal munidos dos medicamentos de que podem necessitar durante o tempo de permanência no torrão natal. Claro que isto não significa que, em caso de necessidade, não procurem os médicos e os serviços de saúde em Portugal para se tratarem, guardando embora como principal referência 
as orientações dos médicos que os seguem em França, chegando a comunicá-las aos médicos que consultam em Portugal. Porém, mantêm sempre uma tendência para confrontar ou comparar ambos os sistemas de saúde e o comportamento dos respectivos médicos, valorizando mais os franceses, tanto pela sua operacionalidade, como pela qualidade das relações que mantém com eles, assim como os benefícios da Segurança Social.

Paralelamente a esta estratégia, não será despropositado fazer notar que as duas grandes razões evocadas para adoptarem este tipo de comportamento migratório são idênticas às daqueles que decidiram fixar-se em França: encurtar as distâncias com os filhos e os netos para não repetirem a experiência da separação dos pais, parentes e amigos aquando da sua emigração e continuar a beneficiar das regalias do sistema de saúde francês. Agindo desta maneira, sem sombra de dúvida, que o processo de integração social, é nestes casos mais abrangente, na medida em que congrega os dois países e as duas nacionalidades que adoptaram. Poderá, então falar-se de uma integração social de cariz nacional ou internacional de cariz bipolar?

Mesmo assim, um casal, expressou junto dos filhos a vontade de, após a morte, quererem vir a ser enterrados na terra natal, embora haja cada vez mais portugueses a serem enterrados nos cemitérios franceses, sinal claro de uma integração social bem conseguida. Outro aspecto relacionado com esta problemática tem que ver com o sistema de saúde francês que é, muitas vezes, evocado pelos portugueses em contraponto com o português, para se instalarem definitivamente em França em vez do regresso à terra natal.

Deste modo, não só as pessoas interrogadas como muitas outras com quem falamos fora do quadro das entrevistas, dizem que não pretendem regressar por recearem não serem tão bem tratados quando a doença sobrevem e usufruírem de menores regalias da segurança social, embora também reconheçam que os serviços de saúde em Portugal melhoraram bastante ao longo dos últimos anos, assim como o comportamento dos profissionais de saúde que se mostraram agora mais compreensivos, o que está bem expresso nestes extractos de entrevista.

É verdade que antes de vir para França era ainda novo e, por isso, e praticamente não tinha problemas de doença, o que me levava a ir muito raramente ao médico ou ao Hospital. Como não tinha Segurança social não podia ir à Caixa de Previdência. Quando vim para aqui, em 1971, ainda não havia os Centros de Saúde nem o Serviço Nacional de Saúde, o que me parece ter sido muito bom para a saúde das pessoas em Portugal. Só com o alargamento dos primeiros a várias aldeias foi possível mais pessoas pobres ou remediadas irem mais ao médico, uma vez que aqui as consultas e os tratamentos 
que forem precisos e possíveis são mais baratos e alguns quase de graça. Mas para isso também é preciso estar inscrito na Segurança Social e ter um médico de família. (Homem, operário especializado, 62 anos).

Antes de vir para França tudo era bem diferente. Só se ia ao médico quando alguém estava realmente doente porque era muito caro, assim como os exames que o médico mandasse fazer. Tínhamos imensas dificuldades para arranjar dinheiro para estas despesas. Muita gente antes de ir ao médico tentava recorrer a remédios caseiros. A minha mãe e a minha avó conheciam muitas mezinhas, que eu também aprendi com elas. Às vezes até davam bons resultados, mas noutras nem tudo corria bem e, por isso, só se ia ao médico já muito tarde. Muitos até quando fracturavam algum osso, em vez de irem ao médico ou ao hospital, iam ao endireita. Em França tudo é muito diferente. As consultas são muito baratas, ainda que agora a situação esteja a mudar. Mas para quem tiver uma "mutuelle", ainda que pague qualquer coisa, vem depois a ser reembolsado de tudo. Por isso, agora não precisamos de recorrer às mezinhas caseiras para poupar dinheiro. Quando se está doente vai-se logo ao médico. Mas também aqui os médicos são muito simpáticos e não fazem distinção pelo facto de sermos portugueses. Em Portugal não é assim. Para se conseguir uma consulta é preciso estar imenso tempo à espera e os médicos fazem mais distinção entre as pessoas. Quem for rico e puder pagar uma consulta pode ser logo atendido. Quem não puder que espere. Mas também parece que as coisas estão agora a melhorar em Portugal, mas se nas férias precisarmos de ir ao médico e comparamos com o que se passa em França ainda há uma grande diferença [...] Por tudo isto e porque também os filhos e os netos estão cá, decidi com o meu marido ficar em França. Sentimo-nos cá bem e agora dificilmente nos readaptávamos em Portugal (Mulher, porteira, 59 anos).

Em termos de síntese, destes comentários podemos extrair três aspectos fundamentais.

0 primeiro tem que ver com a experiência vivida em Portugal antes da emigração em que os emigrantes portugueses que foram para França, gozando de boa saúde ou não tendo recursos económicos para o efeito, raramente contactavam o médico ou outros serviços de saúde. Nessa época não se investia na prevenção como hoje ou como o fazem em França, tendo em conta os efeitos do processo de aculturação de que vão beneficiando. Igualmente foram deixando de atribuir tanta importância à medicina popular praticada no seio da família.

0 segundo prende-se com o desconhecimento da transformação do sistema de saúde em Portugal, designadamente desde os finais dos anos setenta do século XX, quando foi criado o Sistema Nacional de Saúde, e a sua universalidade, tendendo os serviços prestados a serem tendencialmente gratuitos. Não chegando a fazer esse 
acompanhamento, ao compará-lo com o francês, aliás o único que conhecem bem e de que mais beneficiam, tendem ainda a acentuar mais o que os distingue do que o que os aproxima. Seja como for, em França mostram-se mais consumidores de serviços de saúde quase ou mesmo gratuitos, com alguma excepção para os cuidados de medicina dentária que são muito mais caros em França do que em Portugal. Por outro lado, para a grande maioria foi em França que pela primeira vez acederam aos benefícios da Segurança Social, em virtude de uma actividade profissional assalariada. Trata-se de um direito que, conferindo uma cobertura das despesas com a doença, confere 0 acesso aos cuidados médicos e à baixa. Doravante, a Segurança Social garante o direito à doença, o que raramente acontecia antes da emigração. De resto, Parsons (1951) com a sua noção de "papel do doente" formula uma concepção centrada no valor positivo da medicina e do recurso ao médico, isto é, defende que na sociedade moderna 0 indivíduo tem direito a estar doente. Então, está exempto das suas responsabilidades, em particular das de produção.

Está-se também já, aqui, perante uma consequência expressiva da mudança da operacionalidade dos serviços de saúde em Portugal, uma vez que com a universalidade do Serviço Nacional de Saúde todos têm direito aos serviços de saúde públicos: dos centros de saúde, dos hospitais e a grande maioria dos benefícios da Segurança Social.

Finalmente, depreende-se que o modo como valorizam estes serviços e a saúde em geral, constitui um factor fundamental de decisão logo que se põe a questão do regresso ou da fixação em França, optando mais por esta última. Deste modo, dão mais força e consistência ao processo de integração social em França onde pensam continuar a viver junto dos familiares mais próximos, dos amigos e de outras redes de relações sociais que aqui foram criando.

\section{Em Jeito de Conclusão}

A ideia corrente que consiste em querer tornar a população responsável pela sua saúde assume particular significado para os imigrantes, uma vez que são sobretudo considerados como bomo faber. Daí que o trabalho e a saúde, duas vertentes extremamente imbricadas, sejam consideradas condições essenciais da sua existência, tanto pelos próprios imigrantes e as entidades patronais, como pela sociedade envolvente, na medida em que é através delas que se tornam rentáveis, ao invés da doença que é incapacitante.

Neste estudo, tomando como caso ilustrativo o dos portugueses em França, entre outros aspectos constatamos que, valorizando imenso a saúde e os respectivos serviços nacionais, fazem destes elementos uma condição determinante da realização dos seus 
projectos e do seu sucesso, quer aos olhos da sociedade que os viu partir, quer da sociedade francesa onde vivem e onde se foram instalando de maneira definitiva. Neste sentido, na inter-confluência do económico e da saúde emerge um laço estreito entre estas vertentes e a integração social. Esta, sendo um processo bi-unívoco, convoca igualmente o empenhamento dos portugueses e da sociedade francesa, pois quanto mais aberta esta se revelar mais harmonioso se torna este processo. Esta perspectiva acentua um agir em comum e a saúde de índole biológica e social ocupa aqui um lugar de destaque.

Por outro lado, numa organização tão estruturada e hierarquizada como a sociedade francesa, onde todas as prestações não ocupam lugares semelhantes, os imigrantes, portugueses, dificilmente se vêm atribuir o mesmo valor e prestígio quando, por exemplo, não gozam de boa saúde. Nesse caso, em vez de serem considerados uma mais valia para a sociedade, podem antes ser visto como um peso que sobrecarrega a sociedade onde vivem. Daí que a recuperação da saúde, fazendo apelo ao concurso dos serviços de saúde locais, sejam extremamente valorizados e estes últimos venham, também, a influenciar as tomadas de decisão dos portugueses em relação aos projectos de futuro no que se refere ao regresso ou à fixação.

\section{REFERÊNCIAS}

ABOU, Salim. Lidentité culturelle. Relations interethniques et problèmes d'acculturation. Paris: Anthropos, 1981.

ADAM, Philippe; HERZLICH, Claudine. Sociologie de la maladie et de la médicine. Paris: Nathan, 1994.

BASTIDE, Roger. Sociologie des maladies mentales. Paris: Flammarion, 1965.

BOURDIEU, Pierre. La reproduction. Paris: Ed. de Minuit, 1970.

DRULHE, Marcel. Santé et société: le façonnement sociétal de la santé. Paris: PUF, 1996. (Col. Sociologie d'aujourd,hui).

FASSIN, Didier. Précarité. Précarisation et santé. Conférence. Le Monde-les Maures: INSERM, 1997.

FASSIN, Didier. L'espace politique de la santé. Essai de généalogie. Paris: PUF, 1996. (Coll. Sociologie d'aujourd'hui).

GENTILINI, Michel; DUFLO, Bruno. Médicine tropicale. Paris: Flammarion, 1986.

GEORGE, Pierre. As migrações internacionais. Lisboa: Publicações Dom Quixote, 1977. 
GOFFMAN, Erving. Estigma. Notas sobre a manipulação da identidade deteriorada. Rio de Janeiro: Zahar, 1982.

HIACH, Pierre. Expressions des symptoms et conduits de maladie, facteurs sociocultureles et méthodologiques de différentiation. Paris: INSERM/Doin, 1991.

HIACH, Pierre. Justice social ou égalité: l'exemple de la santé. Santé Publique et sciences sociales, v. 2, p. 10-25, 1998.

HERZLICH, Claudine ; PIERRET, Janine. Maladies d'bier, maladies d'aujourd'bui. Paris: Payot, 1984.

HUGO, Victor. Les Misérables. Paris: Cercle du Bibliophile, 1862-1963.

LAZORTHES, Guy. Sciences humaines et sociales. L'homme, la société et la médicine. Paris: Masson, 1998.

LEANDRO, Maria Engrácia. Au-delà des frontières. Famille et immigration. Contraditions et enjeux. Accueillir, n. 199, p. 24-32, 1993.

LEANDRO, Maria Engrácia. Mouvements migratoires au Portugal: À la recherche d'une vie meilleure in Les Hommes, leurs espaces et leurs aspirations. Hommage à Paul-Henry Chombart de Lauwe. Paris: L'Harmattan, 1994.

LEANDRO, Maria Engrácia. Au-delà des apparences. Les Portugais, face à l'insertion sociale. Paris: CIEMI-L'Harmattan, 1992-1995.

LEANDRO, Maria Engrácia. A construção social da diferença. Cadernos do Noroeste, Série Sociedade e Cultura, v. 13, n. 1, p. 5-30, 2000.

LEANDRO, Maria Engrácia. A saúde no prisma dos valores da modernidade. Trabalhos de Antropologia e Etnologia, v. 41, n. 3-4, p. 67-93, 2001.

LEANDRO, Maria Engrácia. Recomposições identitárias e cidadania activa. Novos olhares sobre a situação dos portugueses na região de Nurnberg. Humanística e Teologia, v. 23, p. 287-346, 2002a.

LEANDRO, Maria Engrácia et al. Os males do corpo em terra estrangeira. In: LEANDRO, Maria Engrácia; ARAÚJO, Marta; COSTA, Manuel (Org.). Saúde. As teias da discriminação social. Braga: ICS, 2002b, p. 181-210.

LEANDR0, Maria Engrácia. Desigualdades sociais na saúde e na doença: a questão imigrante. Configurações, n. 1, p.71-86, 2005.

LE BRETON, David. Soins à l'hôpital et différences culturelles. In : CAMILLERI, Carmel ; COHENEMERIQUE, Margalit. Chocs de Cultures: Concepts et enjeux pratiques de l'interculturel. Paris: L'Harmattan, 1989. 
LE BRETON, David. Anthropologie du corps et modernité. Paris: PUF, 1990.

LE DISERT, Dominique. La maladie: la part du social. Paris: éditions du CDSH, 1985.

LOPES, Henriques et al. Gestão da Doença \& Qualidade em Saúde. Lisboa: Comissão Sectorial da saúde do IPO, 2000.

MACHADO, Helder. Ciência \& Humanismo. Novo paradigma da relação médico-doente. Coimbra: Almedina, 2003.

MENDES, Anabela. Tuberculose está à solta. Jornal Público, 28 nov. 1999.

NOSSA, Paulo. Geografia da Saúde. 0 caso da Sida. Oeiras: Celta Editora, 2001.

PARSONS, Talcott. Social structure and dymamic process: de case of modern medical practice. Glencoe, Illinois: The Free Press, 1951. (The social system. Texte ${ }^{\circ} 10$ ).

QUARTILHO, Manuel. Cultura, Medicina e Psiquiatria. Coimbra: Quarteto, 2001.

SARTRE, Jean-Paul. Questions de méthodes. Paris : Gallimard, 1986.

SAYAD, Adelmalek. Les trois âges de l'émigration algérienne en France. Actes de la Recherche en sciences sociales, v. 15, p. 59-79, juin 1977.

SAYAD, Adelmalek. La double absence. Des illusions de l'émigré aux souffrances de l'immigré. Paris: Seuil, 1999.

SONTAG, Susan. La maladie comme métaphore. Paris: Le Seuil, 1980

THOMAS, Louis-Vincent. La mort en question. Traces de mort, mort des traces. Paris: L'Harmattan, 1991.

TOURAINE, Alain. La voix et le regard. Paris: Seuil, 1978.

WEBER, Max. Économie et Société. Paris: Plon, 1971. 